COMMENTARY

\section{Fighting for the taste buds of our children}

\author{
A-dae Romero-Briones * \\ First Nations Development Institute
}

Special JAFSCD Issue

Indigenous Food Sovereignty in North America

sponsored by

\section{Swette Center for \\ Arizona State University}

\begin{abstract}
In this commentary, I focus on the impacts of Indian boarding school food on American Indian foodways and community as a source of acculturation that has a lasting effects even in the present day. From the introduction of specific foods that now make up the modern diet of many American Indian communities, to the generational cycle that begins in utero, the taste buds of American Indian children are still subject to the "American Indian Boarding School experiment" that began in the late 1800s. Only American Indian communities can determine when that experiment stops.
\end{abstract}

\section{Keywords}

American Indian Foodways, Nutrition, Indian Boarding Schools, Children's Food Preferences, Indigenous Food Systems

* A-dae Romero-Briones, JD, LLM (Kiowa/Cochiti), Director of Programs, Native Agriculture and Food Systems Initiative, First Nations Development Institute; 2432 Main Street, $2^{\text {nd }}$ Floor; Longmont, CO 80501 USA; +1-303-774-7836; abriones@,firstnations.org

\section{Introduction}

This commentary is informed by my experience in the backyard of my grandmother's home in front of an old steel stove that she used in summertime to cook all the family meals. The stove was gifted to her from her mother, my great-grandmother. My great-grandmother received the same stove from her father, Cyrus Dickson, who was one of three Cochiti students who attended Carlisle Indian School in Carlisle, Pennsylvania. He attended from 1881 to 1887 . The stove required that its firewood be cut into small pieces and had plates that my grandmother lifted to control the temperature. It was very much like the stove she used in home economics classes when she was a student at Santa Fe Indian School in the 1930s. My great-grandmother was one of the first ladies in the village to have a steel stove. She cooked blue corn tortillas, posole, dried jerky, and a wide range of other foods on that stove for both the family and the community. While researching the journey of my greatgreat-grandfather and the journey of countless American Indian children who were sent to Carlisle Indian School, I came across pictures of well- 
dressed students sitting at formal dining tables with white tablecloths and candles, a far cry from any meal I ever had as a child in Cochiti, a subsistence agricultural community that is centered on traditional Pueblo agriculture. In wintertime when it was too cold to cook outside, my grandma would be forced to use the indoor gas stove, and the steel stove outside would be covered in a thin layer of ice waiting to be re-ignited. The stove was modern, but it required wood and fire to be functional. It came to remind me of my great-great-grandfather's journey. One summer night, my grandmother asked me what I would like of her possessions upon her passing. Without hesitation, I asked for the stove.

Thirty years later, I was working at First Nations Development Institute with Indigenous communities on community food projects. First Nations Development Institute has been supporting community-based food and agricultural projects throughout Indian Country since 2007. Through grant programming, over 305 American Indian community-based food projects that focus on community gardens, healthy eating, traditional foods, food policy development, health promotion, nutrition education, and community agricultural education programs have been supported. Each program has submitted written reports on its challenges, insights, and findings. Working in this space since 2007 , I have found that there are similarities, trends, and consistencies that have emerged in this field. While the communities have varied in geography, region, language, and culture, their challenges seemed to be wholly consistent.

\section{Food in Indigenous Society and the Impact of Boarding Schools}

Food and its role in Indigenous community and society are critical in understanding the changes within that community and society once a diet is changed. First Nations Development Institute, a national nonprofit, has been funding Native food and agriculture projects throughout the United States since 2007. Through the development of this work portfolio and with input from over 300 Indigenous communities over the life of the initiative, First Nations Development Institute has developed a model of an Indigenous food system that is generally described here in Figure 1.

Generally, food is an integral Indigenous societal "sensor" in that it is closely tied to basic societal institutions in Indigenous communities. In historical times, Indigenous communities were directly tied to their food sources because their society was organized around the growing, harvest, and hunting seasons. Clans, families, and entire communities were organized in ways to optimize access and regulate food to ensure that the land, plants, animals, fish, and water were harvested in balance for continued growth of the community (Cajete, 1999). In economic institutions, food was used as a valued product that could be traded internally within the community and externally outside of the community. Extensive trade routes were established that allowed intratribal and intertribal trade to thrive (Swentzell \& Perea, 2016). These trade routes were based largely on food items. In spiritual institutions, Indigenous communities tie many of their first foods to creation stories and frequently time ceremony with food seasons based on times for hunting or gathering or harvesting of food (Cajete, 1999; Kimmerer, 2013; Swentzell \& Perea, 2016). In political institutions, food was often managed by clan or familial systems so that there was some accountability of consumption and redistribution (Cajete, 2000). Political leadership and appointments were pulled from roles within the food system. In educational institutions, some of the first lessons young Indigenous children were taught were based on food, whether it be through the recital of creation stories that may have included important foods or whether it be environmental understandings through food gathering, hunting, or harvesting (Cajete, 2000). Lastly, social values were taught through food, whether it be the understanding of certain foods to be used for specific occasions, sharing, cooking, or using food as a social behavior re-enforcement.

Because of the close ties to food sources, Indigenous people often understand the growth cycles of food. All elements that sustain these cycles are collective resources. These elements are intergenerational knowledge, water, land, human and animal interactions, sky, and physical ability to cultivate. The elements belong to no one; they produce foods, a basic necessity of existence. For 
Figure 1. Indigenous and Mainstream Food Systems Compared

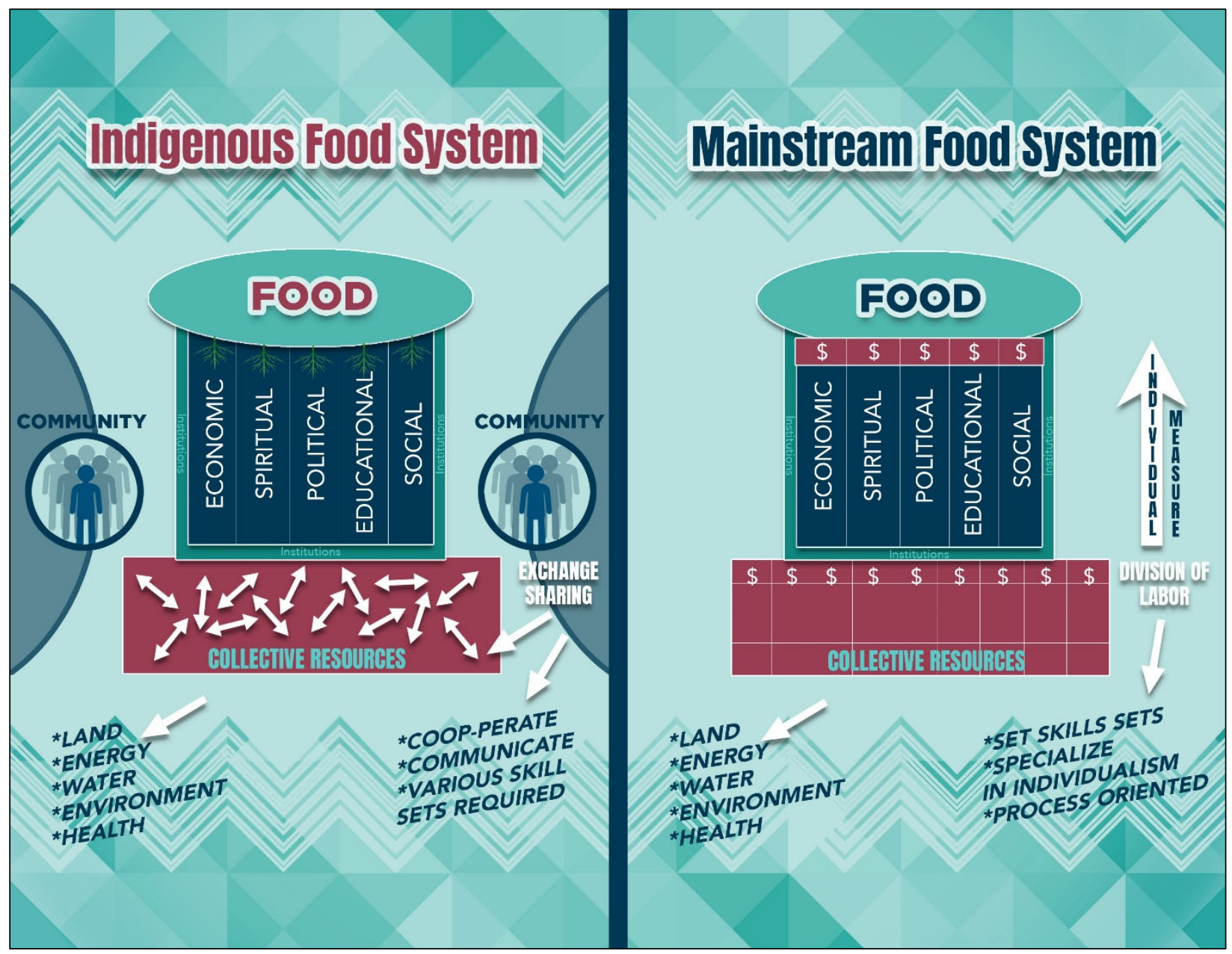

Created by A-dae Romero-Briones, First Nations Development Institute.

example, corn cannot grow without human or animal interaction, sunlight, water, and earth. These environmental and external sources are the basic elements of creation that are viewed as shared resources and are available for everyone to utilize in order to grow the corn. Because of the recognition of collective resources, community and individual interactions become pivotal in a well-functioning society (Cajete, 2000). Cultural norms, social norms, and basic understandings of community are centered on communication skills that are often encoded into ceremony, relationships, and community gatherings (Cajete, 2000). Presence and participation are of utmost importance to understanding and purposely managing collective resources (Cajete, 2000). If the societal institutions are functioning properly and collective resources are available and managed properly, the members of the community ideally will have access to food. In short, participation and interaction in the community blossom into an Indigenous food system.

While the nature of food has changed over time, food as an indicator in an Indigenous society largely remains the same in that it can be used to determine the health and relevance of a societal institution. The system of American Indian boarding schools did much damage in every one of the basic institutions that made up Indigenous society, but most scholarship focuses on the educational institution. Extracting children from their Indigenous food system essentially creates individuals devoid of an understanding of their land, environ- 
ments, political systems, education systems, and spiritual systems, and no understanding of collective resource management. Essentially, that is what the American Indian boarding school system aimed to do-acculturate Indigenous children into "their allotted role" in American society and "stamp out all things indigenous" (DeJong, 2007, p. 257), including their relationships with their families, communities, lands, and foods. As a result, the taste preferences of Indigenous children transformed from one based on traditional food systems with live connections to community and place to one that is transformed by military science and diet that was dependent on fat, sugar, and carbohydrates. Presently, the boarding school diet prevails in almost every Indian community, is a primary source of chronic health conditions, and is one of the larger barriers to establishing healthy diets and community-determined food systems in Indian Country.

\section{Children's Food Preferences}

Prior to contact, Indigenous communities had established food systems that were imbedded in their regions and environments. Diets within a given community were quite similar, if not identical, thus allowing the community to build institutions upon these food systems that reflected the values of the community to establish cultures in tune with land, environment, and the human existence within that environment. Culture, defined broadly, is "the characteristic features of everyday existence (such as diversions or a way of life) shared by people in a place or time" ("Culture," n.d., para. 2). Indigenous children born to Indigenous communities usually became members of their community through ceremony, family, community, and, ultimately, participation in the very food system that sustained their mothers during pregnancy and prior generations. This cycle of creation, re-creation, and maintenance of both the community and environment was the mainstay of Indigenous life.

Children, while in utero, were already learning to "taste" the nature and character of their food system, community, environments, and were being prepared to participate in them as consumers of the foods that are the epicenter of that system.
Dr. Julie Mennella, a researcher who studies in utero and infant tastes, states, "Each individual baby [within the womb] is having their own unique experience, it's changing from hour to hour, from day to day, from month to month. As a stimulus, it providing so much information to that baby about who they are as a family and what as the foods their family enjoys and appreciates" (Cuda-Kroen, 2011). In Indigenous communities, food preferences were also reflective of the community that is embedded in a particular environment. In short, pregnant women in Indigenous communities consumed what was readily available in their Indigenous food system, exposing children to the tastes that would tie their human necessities to the perpetuation of their Indigenous society. This process also continued after birth.

One of the most critical periods of growth and learning is early childhood. All senses are fully active, allowing the child to learn about their world, family, environment, and society. Understanding the environment through food is an essential base of knowledge that allows Indigenous children to understand how their community and society is structured. Traditional foods coincide with specific seasons, which in turn, reflect lessons about resource management, allowing children to witness the managers and societal structures around that management. Mennella further explains that, "In other words, characteristic flavor of the formula experienced in early life is 'imprinted' and remains as a preference for considerable time" (Beauchamp \& Mennella, 2011, p. 3). Taste and food become an important base for understanding throughout an Indigenous child's lifetime.

Additionally, taste and exposure to foods that support the Indigenous society become a critical measure of individual health. Beverly Cowart (1981) states that taste acts as a bodily regulatory process, noting that "specific taste preferences are undoubtedly important in the regulation of food intake" (1981, p. 57). A child who "grows" their tastes that derive from their environment that is fundamental to their family, community, and society then becomes a critical participant in all those structures, which are then perpetuated by the child's health. While the growth of "taste" begins even in utero, there are critical periods of taste and 
preference influence, one of those times being the tastes introduced in utero and another of those times in adolescence (Garb \& Stunkard, 1974).

Research suggests that there are stages in young adolescence when individuals begin to develop their own preferences, particularly in periods of increased independence and greater susceptibility to peer influence. "There is suggestive evidence that late childhood/early adolescence may be a particularly interesting period in the development of taste preferences" (Garb \& Stunkard, 1974, p. 67). This confirms more recent studies that identify perceived taste sensitivities at different age categories. These category differences are in young adult, young-old, and old-old populations (Yoshinaka et al., 2016). While the physical and physiological changes occur in adolescents' perception of tastes, they are also at a period when they are developing adult dietary habits. Johnson (2016) states, "Indeed, the few longitudinal studies that assess children's food preferences suggest that food preferences acquired during early childhood carry on into adolescences and predict the quality of diet in

Figure 2. A Facebook Post Dated January 8, 2019, in a Group Called "Fry Bread Factory," Described as a Page "Created for the 7th Generation and All Our Relations"

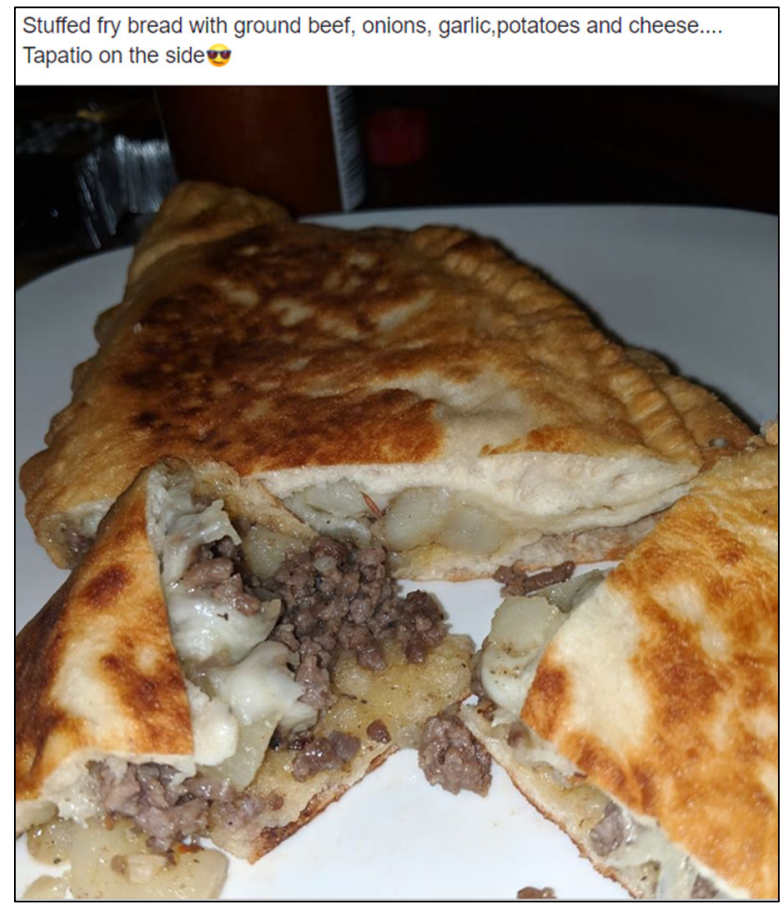

adult years" (p. 221S). In short, adolescence is not only a period of physical transition but also social transition, and is a critical transition period of childhood dietary patterns into adulthood.

Thus, American Indian boarding schools of the $20^{\text {th }}$ century have had a slow, but targeted and steady impact on the transformation of Indigenous foodways. This transformation is still slowly grinding along, and its impacts are clearly visible in our community today.

Indeed, as a result of boarding schools and federal Indian policy, the present-day diet for Indigenous communities is uniformly unhealthy. Every community has a version of fry bread, the product of mixing white flour and sugar and frying it in lard, all ingredients that are rampant in Indian boarding school classrooms (see Figure 2). Every federally recognized tribe has some access to the federal feeding program, the Food Distribution on Indian Reservation Program, which only further standardizes the Indigenous diet and palate. Furthermore, the cooking skills and the expectation of behaviors around food and meals taught at boarding schools are still widely practiced in Indigenous homes across the country.

One of the prime areas of current health research in American Indian communities is diet. Story et al. (1999) state, "Obesity has become a major health problem in American Indians only in the past 1-2 generations and is believed to be associated with a relative abundance of high-fat foods and the rapid change from active to sedentary lifestyles" (Story et al., 1999, p. 747S). The study described the dietary practices that were identified as contributing to obesity. These included the consumption of butter, lard, whole milk, fry bread, fried meats and vegetables, and the generous use of fat in beans (Story et al., 1999). Not coincidentally, the foods mentioned are the same foods provided for in the 1776 army ration box and were the same foods used to feed students in American Indian boarding schools. The diet of the American Indian boarding school was so ingrained because of acculturation that students returning home took those taste preferences and dietary practices into their community, leaving taste preferences and dietary practices that have lasted for generations. 
In a more recent study on food perceptions and dietary behavior of American Indian children, Gittelsohn et al. (2000) found that there was a high level of consensus and a single cultural model of diet that consisted of "an abundance of high-fat, high-sugar foods" (p. 1) despite the geographic variability of the study. The researchers were surprised that few traditional foods were even mentioned by the children in the study (Gittelsohn et al., 2000). They note,

This assessment employed a combination of qualitative and quantitative methods (including direct observations, paired-child-in-depth interviews, focus groups with child caregivers and teachers, and semi structured interviews with caregivers and food service personnel) to query local perceptions and beliefs about food commonly eaten and risk behaviors associated with childhood obesity at home, at school, and in the community. An abundance of high-fat, high-sugar foods was detected in the children's diets described by caregivers, school foodservice workers, and the children themselves. (Gittelsohn et al., 2000, p. 1)

They further found that despite being in six different communities across the nation, the children showed "remarkable consistency in their selection of salient foods and how these foods should be grouped" (Gittelsohn, 2000, p. 11). In the study, the most frequently mentioned foods included hamburger, soda pop, tacos (frequently referred to as Indian tacos) (Gittelsohn et al., 2000, Table 2). Another study of Mohawk children in Akwesasne, New York, found that their diets exceeded recommended intakes for energy, fat, and saturated fat (designated as Fat, Protein, and Carbohydrates) (Harvey-Berino et al., 1997, p. 4). While the American Indian boarding school experience has largely been condemned publicly, with survivors addressing long held emotional traumas, the diet introduced to Indian children in these schools persists.

\section{Impacts of Contemporary Diet}

Presently, there are 573 federally recognized tribes in the U.S. with a total population of 2.9 million
(National Congress of American Indians, n.d.). There are many studies that recount the health disparities of Tribal communities. The Indian Health Service (2018), the federal agency responsible for providing health care delivery, states,

The American Indian and Alaska Native people have long experienced lower health status when compared with other Americans. Lower life expectancy and the disproportionate disease burden exist perhaps because of inadequate education, disproportionate poverty, discrimination in the delivery of health services, and cultural differences. These are broad quality of life issues rooted in economic adversity and poor social conditions.

Diseases of the heart, malignant neoplasm, unintentional injuries, and diabetes are leading causes of American Indian and Alaska Native deaths (2009-2011).

American Indians and Alaska Natives born today have a life expectancy that is 5.5 years less than the U.S. all races population (73.0 years to 78.5 years, respectively).

American Indians and Alaska Natives continue to die at higher rates than other Americans in many categories, including chronic liver disease and cirrhosis, diabetes mellitus, unintentional injuries, assault/homicide, intentional self-harm/suicide, and chronic lower respiratory diseases.

Given the higher health status enjoyed by most Americans, the lingering health disparities of American Indians and Alaska Natives are troubling. In trying to account for the disparities, health care experts, policymakers, and tribal leaders are looking at many factors that impact upon the health of Indian people, including the adequacy of funding for the Indian health care delivery system. (para. 2-5)

The statement summarizes the current state of health in American Indian communities often linked to diet, the diet that was introduced to American Indian children in boarding schools and has since become the preference across communities. In the Akwesasne study, the major finding was that food preferences are the strongest predictor of 
reported eating behavior in very young children and such a finding has strong implications for behavior change interventions (Harvey-Berino et al., 1997). Ironically, the study is almost suggesting that the very same systematic intervention, institutional introduction of specific foods, that was deployed in American Indian boarding schools on American Indian children to disrupt connections to traditional food systems and community in the first place should be used presently to increase intakes of healthier foods.

\section{Re-Educating Our Taste Buds}

While education curriculum and academic subject matter have been re-envisioned to empower American Indian children in Indigenous communities, few movements or strategies have actively focused on taste preferences of Indigenous children. Some of the initial projects around food began as early as 1997 with the Day Break Farming and Food Project in the Iroquois Six Nations. In 2007, First Nations Development Institute initiated the Native Food and Agricultural Initiative (NAFSI) to support community food projects throughout Indian Country. Since NAFSI began, over 305 food and agricultural projects have been supported in the program. Many of the projects funded are community gardens, food policy work, propagation of traditional foods, and agricultural production skillbuilding in Indian community. Only a handful of those projects focus on "taste preferences" or the embracing of traditional food in the curriculum of tribally based schools or programs. Some of the most prominent and thoughtful programs that are working to reintroduce food into education are the Keres Children's Learning Center (KCLC) in Cochiti Pueblo, New Mexico, and the Akwesasne Freedom School in Hogansburg, New York.

The KCLC, the first Indigenous heritage language Montessori school, uses a holistic approach to language education. Its guiding principles are:

- KCLC practices traditional Cochiti beliefs about food, food preparation, eating, serving, and exercise.

- KCLC believes it is important to train children's minds and palates through good nutrition and cooking experiences at school, preparing and tasting healthful alternatives to unhealthy foods.

- KCLC supports families in developing healthy eating habits.

- KCLC provides children with authentic opportunities for movement and other physical activities that will help prevent future health problems such as diabetes, obesity, and coronary disease. (T. Moquino, personal communication, January 2019)

KCLC has consciously incorporated diet and traditional, social, and cultural practices around food, and acknowledges the relationship between education, food, and societal institution-building. It focuses its efforts on the concept that traditional values, community, and Pueblo lifeways support the healthy development of children in daily life. Trisha Moquino (Cochiti/Santo Domingo/Ohkay Owingeh), co-founder of KCLC, says, "Our cook often cooks traditional foods from $500+$ years ago to what has become traditional in terms of using more beef, pork, and chicken with the intro of what Spanish brought" (Moquino, T., personal communication, January 2019). Founded in 2006, KCLC has promising results, but more importantly, it has purposefully re-instituted a learning environment reflective of the community and educated children in the tenets, environments, foods, and cultural and social values of the community.

Similarly, Akwesasne Freedom School was created to perpetuate Mohawk lifeways. Its mission is to "create a place for wholly Mohawk education." Founded in 1979, the school founders consciously founded the school to rebuild the nation and reverse the assimilation process (Sargent, 2007). For example, the school day begins with the Oben:ton Kariwabtekwen (words that come before all else: thanksgiving address) which is a traditional practice that acknowledges a respect for all things, most notably some of the traditional foods and practices around those foods. Additionally, the school garden is a critical classroom where students grow, eat, and maintain the garden daily, and where they learn traditional medicinal plants and reflect on relationships between their natural world and human interaction. These skills and experiences are reflective of a nation's institution-building, the very 
experiences and skills the Indian boarding school diet has sought to weaken.

\section{Conclusion}

Indigenous communities are often the subject of deficit-based health and education studies that document the incredible disparity that we face daily in Indigenous communities. What is not documented is the resilience, the strength, the beauty, and the happiness that are still alive and well in these communities. While some connections to the past and pre-contact lifestyle are fleeting, the base of that system remains intact as demonstrated through the many projects that focus on traditional lifeways, diets, community gardens, and food systems. Research on obesity and diabetes often focus on the individual actions that patients can take to address a health crisis widely spread throughout Indian Country; however, that may be another version of the assimilation process-separating the individual from the community. A prime cause of such health disparities, the diet, was purposefully introduced to create soldiers out of American Indian children. Coincidently, American Indians serve the military at higher than average rates, which is a testament to the effectiveness of the great American Indian education experiment con- ducted by Henry Pratt (the founder of Carlisle Indian Industrial school), which sought to indoctrinate American Indian students in the whole of American citizenry through military regimentfrom diet to values. As new generations of American Indian students arise, we must just as purposefully decide when the experiment ends.

Trisha Moquino started KCLC in 2006, after years of teaching in public schools and Bureau of Indian Education schools. After having two daughters who attended local schools for years, she thought deeply and critically about what kind of education she wanted to provide for her two Pueblo daughters. KCLC was borne out the love for her children, her community, and an unknown hope for the future all Cochiti children. In the same way, American Indian communities across the country must think critically and deeply about the history, loss, love, and hope we have for all Indigenous children. We must build schools, education programs, community gardens, and experiences that allow our children to experience the world that begins with the taste of our community, environment, connections, and history. While it may seem like an insurmountable issue to address, it can all begin with one meal.

\section{References}

Beauchamp, G. K., \& Mennella, J. A. (2011). Flavor perception in human infants: Development and functional significance. Digestion, 83(Suppl. 1), 1-6. https://doi.org/10.1159/000323397

Cajete, G. (Ed.). (1999). A people's ecology: Explorations in sustainable living. Santa Fe, New Mexico: Clear Light.

Cajete, G. (2000). Native science: Natural laws of interdependence. Santa Fe, New Mexico: Clear Light.

Cowart, B. (1981)."Development of taste perceptions in humans: Sensitivity and preference throughout the life space. Psychological Bulletin, 90(1), 43-73. https://doi.org/10.1037/0033-2909.90.1.43

Cuda-Kroen, G. (2011, August 8). Baby's palate and food memories shaped before birth [Newscast episode]. National Public Radio, Morning Edition. Retrieved from https://www.npr.org/2011/08/08/139033757/babys-palate-andfood-memories-shaped-before-birth

Culture. (n.d.). In Merriam-Webster's online dictionary. Retrieved November 2019 from https://www.merriam-webster.com/

DeJong, D. H. (2007). "Unless they are kept alive": Federal Indian schools and student health, 1878-1918. The American Indian Quarterly, 31(2), 256-282. https://doi.org/10.1353/aiq.2007.0022

Garb, J. L., \& Stunkard, A. J. (1974). Taste aversions in man. American Journal of Psychiatry, 131(11), $1204-1207$. https://ajp.psychiatryonline.org/

Gittelsohn, J., Toporoff, E. G., Story, M., Evans, M., Anliker, J., Davis, S., . . White, J. (2000). Food perceptions and dietary behavior of American-Indian children, their caregivers, and educators: Formative assessment findings from Pathways. Journal of Nutrition Education, 32(1), 2-13. https://doi.org/10.1016/S0022-3182(00)70504-8

Harvey-Berino, J., Hood, V., Rourke, J., Terrance, T., Dorwaldt, A., \& Secker-Walker, R. (1997). Food preferences predict eating behavior of very young Mohawk children. Journal of the American Dietetic Association, 97(7),750-753. https://doi.org/10.1016/S0002-8223(97)00186-7 
Indian Health Service. (2018). Disparities. Retrieved November 2019 from https://www.ihs.gov/newsroom/factsheets/disparities/

Johnson, S. L. (2016). Developmental and environmental influences on young children's vegetable preferences and consumption. Advances in Nutrition, 7(1), 220S-231S. https://doi.org/10.3945/an.115.008706

Kimmerer, R. W. (2013). Braiding sweetgrass: Indigenous wisdom, scientific knowledge, and the teachings of plants. Minneapolis, Minnesota: Milkweed.

Sargent, E. (2007, September). The Akwesasne Freedom School. Presentation at the Honoring Nations Symposium sponsored by the Harvard Project on American Indian Economic Development at the John F. Kennedy School of Government, Harvard University, Cambridge, Massachusetts. Retrieved from https://nnigovernance.arizona.edu/honoring-nations-elvera-sargent-akwesasne-freedom-school

Story, M., Evans, M., Fabsitz, R. R., Clay, T. E., Holy Rock, B., \& Broussard, B. (1999). The epidemic of obesity in American Indian communities and the need for childhood obesity-prevention programs. American Journal of Clinical Nutrition, 69(4), 747S-754S. https://doi.org/10.1093/ajcn/69.4.747S

Swentzell, R., \& Perea, P. M. (2016). The Pueblo food experience cookbook: Whole food of our ancestors. Santa Fe: Museum of New Mexico Press.

Yoshinaka, M., Ikebe, K., Uota, M., Ogawa, T., Okada, T., Inomata, C., . . Maeda, Y. (2016). Age and sex differences in the taste sensitivity of young adult, young-old and old-old Japanese. Geriatrics \& Gerontology International, 16(12), 1281-1288. https://doi.org/10.1111/ggi.12638 